\title{
Perancangan Prototype Sistem Control Penyiram Bibit Tanaman Berbasis Arduino Atmega 328
}

\author{
Rendra Soekarta ${ }^{* 1}$, Irman Amri ${ }^{2}$, Reza Mochammad Said ${ }^{3}$ \\ 1,3Program Studi Teknik Informatika, Universitas Muhammadiyah Sorong \\ ${ }^{2}$ Program Studi Teknik Industri, Universitas Muhammadiyah, Sorong \\ e-mail: $\underline{1 \text { rendrasoekarta@gmail.com, }}$ irmanamri1@gmail.com,3rezainformatics@.gmail.com
}

\begin{abstract}
Abstrak
Pembudidayaan bibit tanaman di Madrasah Aliyah Negeri Model Sorong yang dilakukan sekelompok organisasi pelajar pecinta alam, mereka masih menerapkan cara penyiraman bibit yang manual, hal ini membutuhkan tenaga dan waktu yang lebih banyak. Sehingga kurangnya waktu yang dimiliki masing-masing anggota untuk menyiram secara rutin dan di waktu sore hari. Maka dari itu bibit menjadi terhambat dan bahkan tidak berhasil tumbuh dengan baik. Sehingga di buatlah sistem penyiram bibit tanaman otomatis dengan mengontrol kelembaban tanah jika saat tanah kering pompa air akan hidup dan menyiram bibit tanaman sampai kelembaban tanah basah maka pompa air akan berhenti mengalir.
\end{abstract}

Kata Kunci: Sistem penyiram bibit tanaman otomatis, Pengontrol kelembaban tanah.

\section{PENDAHULUAN}

Sistem penyiraman tanaman umumnya masih dikerjakan secara manual, hal ini membutuhkan $\mathcal{N}_{\text {tenaga dan waktu yang lebih banyak. Masalah yang mengkhawatirkan mengenai penyiraman }}$ tanaman secara manual ini dialami juga oleh Organisasi Pelajar Pecinta Alam (PAPALA) di Madrasah Aliyah Negeri Kota Sorong yang memiliki program pembudidayaan bibit cabai, kurangnya waktu yang dimiliki masing-masing anggota untuk menyiram secara rutin bibit cabai membuat perkembangan bibit menjadi terhambat dan bahkan tidak berhasil tumbuh. Bukan hanya penyiraman yang tidak rutin namun kurangnya pengontrolan pada tanah juga menjadi salah satu alasan pembibitan tidak berhasil. Penanaman bibit memang membutuhkan perhatian khusus karena pada fase awal pertumbuhan bibit perlu dilakukan penyiraman secara rutin bila tanah terlihat kering, terutama pada musim kemarau dan pada saat musim hujan penyiraman disesuaikan dengan kondisi tanahnya. Dengan adanya penyiraman secara rutin inilah dapat menjaga kelembaban tanah.

Penelitian tentang sistem kontrol penyiraman tanaman sudah pernah dilakukan oleh Prayitno (2017), penelitian dilakukan pada tanaman hidroponik dengan menggunakan blynk Arduino. Pada penelitian ini dirancang sistem yang dapat mengontrol kondisi lingkungan tanaman hidroponik dengan menggunakan Ethernet shield untuk pengiriman data melalui internet, kemudian dengan aplikasi khusus android penyiraman tanaman hidroponik ini dapat dipantau dan dikendalikan dari jarak jauh.

Berdasarkan pemikiran di atas, maka diangkatlah pemikiran tersebut dalam penelitian yang berjudul: Rancang Bangun Sistem Penyiram Bibit Tanaman Cabai Otomatis Berbasis Arduino Atmega328 Pada Persemaian PAPALA MAN Kota Sorong. Pada penelitian ini alat yang dibuat akan mendeteksi kelembapan tanah dan kemudian akan otomatis menyiram air pada bibit cabai sesuai dengan kebutuhan. 


\section{METODE PENELITIAN}

\subsection{Blok Diagram}

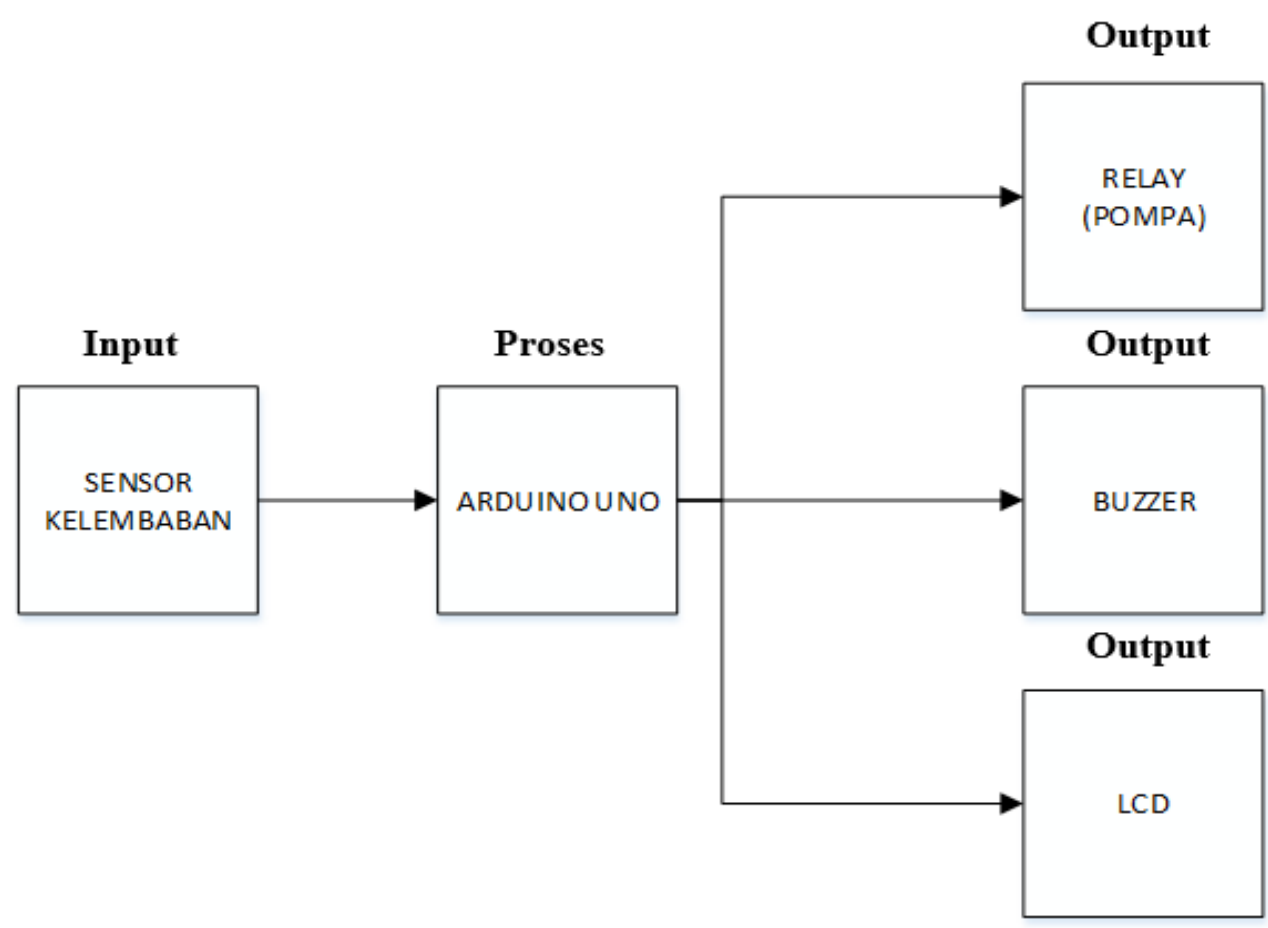

Gambar 1. Blok Diagram

Pada gambar 1 di atas dapat dilihat bahwa Sistema ini menggunakan Microconteller sebagai perangkat proses dari inputan yang diterima dari Sensor Kelembaban. Hasil proses itu akan dieksekusi perangkat ouput yaitu Relay yang akan menghidupkan dan mematikan mesin pompa air dan Buzzer yang akan mengeluarkan bunyi sebagai notifikasi. Serta LCD menampilkan status kelembaban pada tanah. Semua perangkat tersebut akan dihubungkan seperti pada gambar 2 Skema Rangkaian.

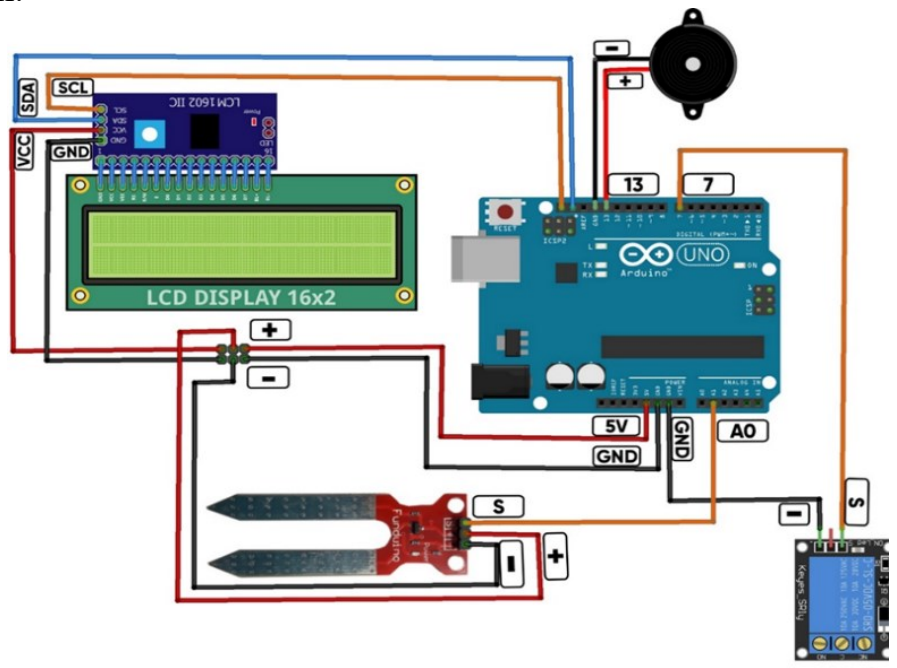

Gambar 2. Skema Rangkaian 
2.2 Flow Chart

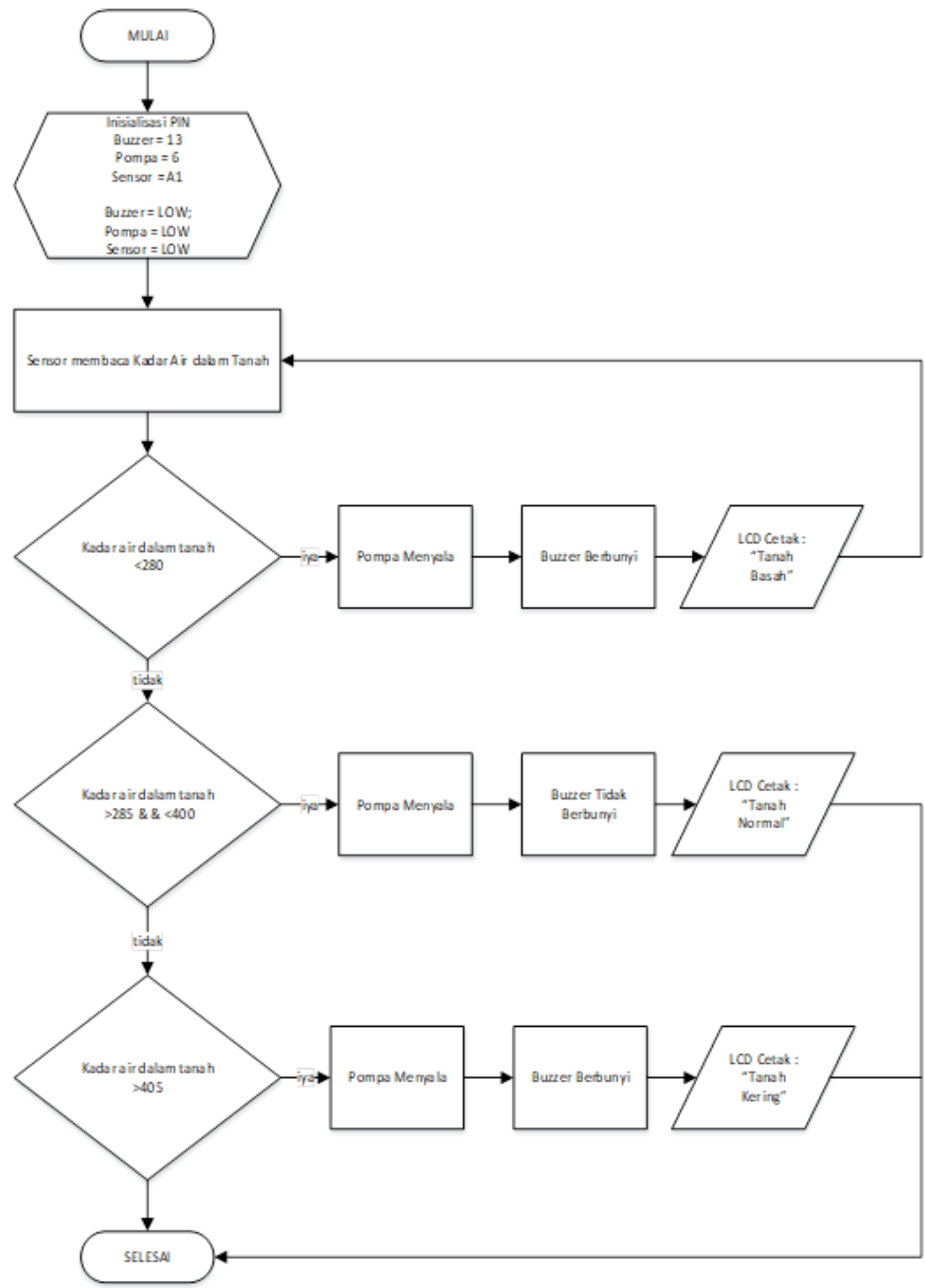

Gambar 3. Flowchart Sistem 


\section{HASIL DAN PEMBAHASAN}

Hasil ini merupakan bentuk Implementasi yang dilakukan dengan menghubungkan semua perangkat dengan mikrokontroller dan juga Power Suplai agar dapat berfungsi dengan baik dan juga memasangnya pada sebuah maket berbentuk seperti tempat pembibitan tanaman. 3.1 Implementasi Rangkaian Sensor Soil Moisture

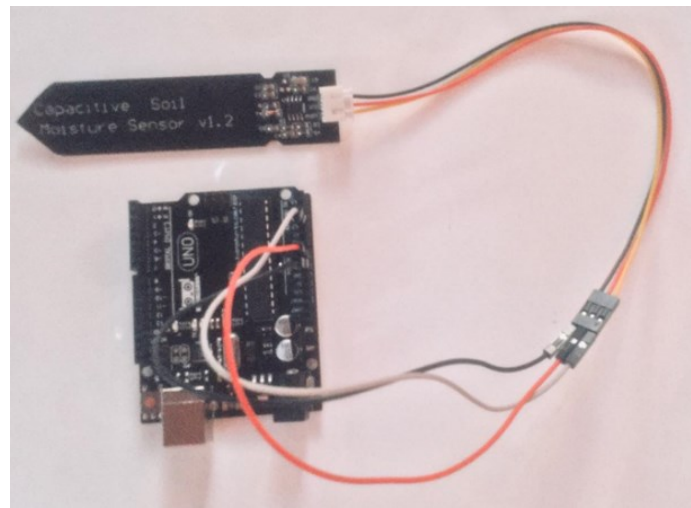

Gambar 4. Rangkaian Sensor Soil Moisture

3.2 Rangkaian Liquid Crystal Display (LCD)

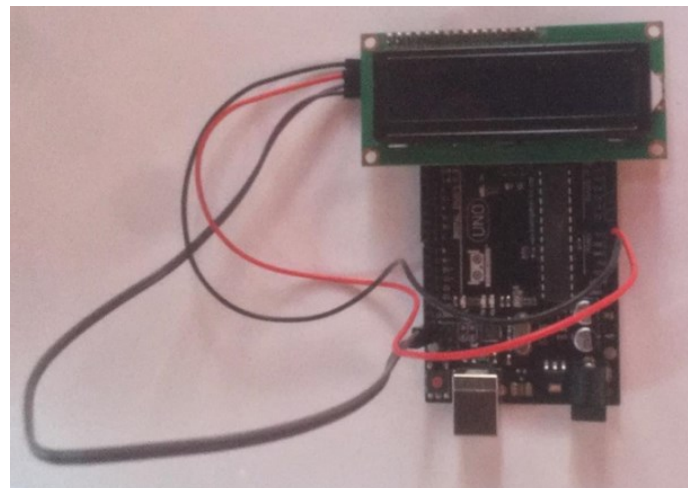

Gambar 5. Rangkaian Liquid Crystal Display (LCD)

3.3 Rangkaian Relay

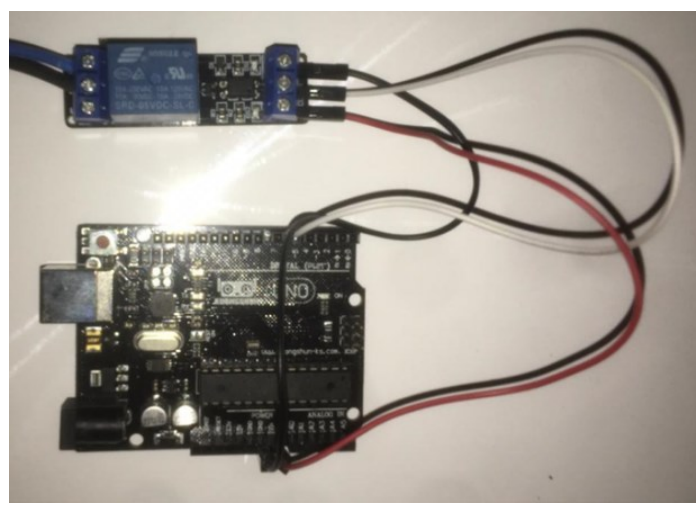

Gambar 6. Rangkaian Relay

3.4 Rangkaian Buzzer 


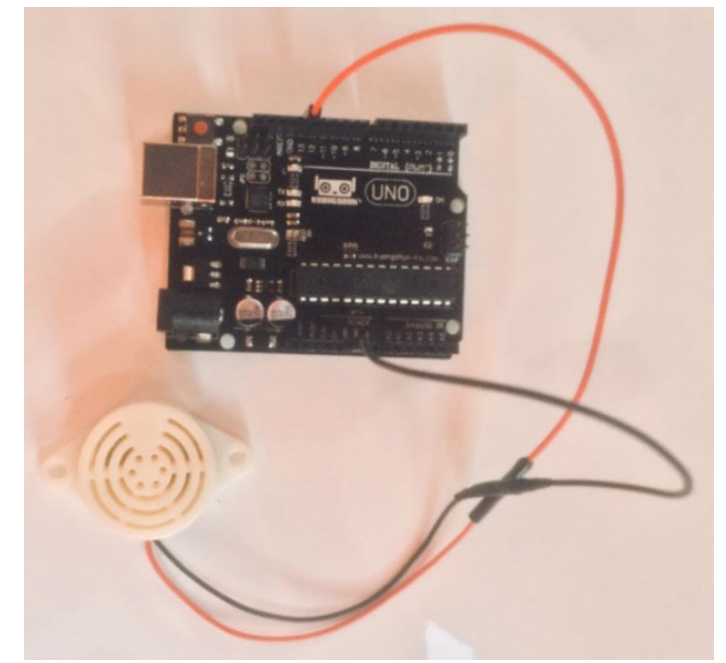

Gambar 7. Rangkaian Buzzer

\subsection{Bentuk Prototype}

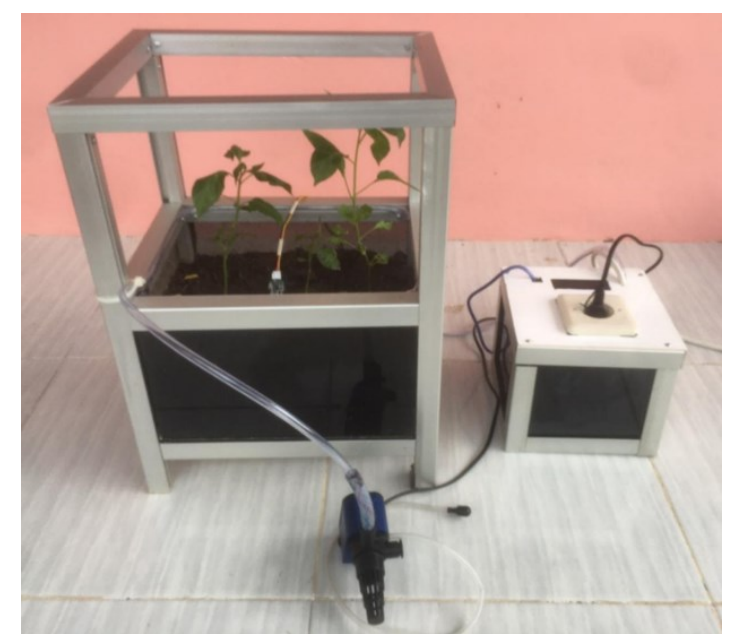

Gambar 8. Bentuk Prototype

\subsection{Pengujian}

Pengujian pada prototype ini dilakukan dengan mensimulasikan proses penyiraman bibit tanaman yang telah terpasang sensor soil moisture di pot atau kotakan pembibitan.

a. Pengujian 1

Pengujian pertama dilakukan dengan membasahi tanah pada tempat pembibitan dan sensor soil moisture mendeteksi kadar air dalam tanah kemudian lcd mencetak "kelembaban : 244 Tanah Basah", buzzer berbunyi dan pompa air tidak menyiram.

b. Pengujian 2

Pengujian kedua peneliti melakukan pengamatan pada tempat pembibitan dan sensor soil moisure mendeteksi kadar air dalam tanah kemudian lcd mencetak "Kelembaban : 345 Tanah Normal" dan pompa air menyala selama 5detik sebanyak 3 kali dengan jeda 3detik, setelah itu pompa tidak menyala hingga $5 \mathrm{jam}$.

c. Pengujian 3

Pengujian ketiga dilakukan pengamatan pada tempat pembibitan dan sebelum 5 jam sensor soil moisture mendeteksi kadar air dalam tanah kemudian lcd mencetak "Kelembaban : 506 Tanah Kering" dan buzzer berbunyi. Maka pompa air menyala selama 5 detik dengan jeda 3detik, hingga LCD mencetak kelembaban normal atau basah setelah itu pompa air berhenti secara otomatis.

d. Pengujian 4 
Pengujian keempat peneliti melakukan pengamatan pada tempat pembibitan dan sensor soil moisure mendeteksi kadar air dalam tanah kemudian lcd mencetak "Kelembaban : 398 Tanah Normal" dan pompa air menyala selama 5 detik sebanyak 3 kali dengan jeda 3 detik, setelah itu pompa tidak menyala hingga ljam kemudian.

e. Pengujian 5

Pengujian kelima peneliti melakukan pengamatan pada tempat pembibitan dan setelah 3jam kemudian sensor soil moisture mendeteksi kadar air dalam tanah kemudian lcd mencetak "Kelembaban : 248 Tanah Basah" dan buzzer berbunyi. Maka pompa tidak menyala hingga lcd mencetak kelembaban tanah normal atau kering setelah itu pompa air menyala secara otomatis.

f. Pengujian 6

Pengujian keenam peneliti melakukan pengamatan pada tempat pembibitan dan sensor soil moisure mendeteksi kadar air dalam tanah kemudian lcd mencetak "Kelembaban : 311 Tanah Normal" dan pompa air menyala selama 5 detik sebanyak 3 kali dengan jeda 3 detik, setelah itu pompa tidak menyala hingga 3 jam.

g. Pengujian 7

Pengujian ketiga dilakukan pengamatan pada tempat pembibitan dan sebelum 3 jam sensor soil moisture mendeteksi kadar air dalam tanah kemudian lcd mencetak "Kelembaban : 496 Tanah Kering" dan buzzer berbunyi. Maka pompa air menyala selama 5 detik dengan jeda 3detik, hingga LCD mencetak kelembaban Normal atau Basah setelah itu pompa air berhenti secara otomatis.

\section{KESIMPULAN}

Dalam penelitian pembuatan prototype penyiram tanaman persemaian berbasis arduino ATmega328, dapat di ambil kesimpulan sebagai berikut :

1. Sensor soil moisture berhasil diintegrasikan dengan mikrokontroler dengan pengkabelan pada pin GND - GND, VCC - 5V dan AUOT - A1. Untuk mendeteksi kadar air dalam tanah dan sebagai inputan untuk tanah kering, normal atau basah.

2. Relay berhasil diintegrasikan dengan mikrokontroler dengan pengkabelan pada pin VCC -7 , IN - 5V dan GND - GND. Untuk menyiram pada saat tanah kering atau normal dan tidak menyiram pada saat tanah basah.

3. Buzzer berhasil berbunyi saat tanah kering atau basah serta LCD berhasil menampilkan keadaan tanah yang dikirim oleh sensor.

\section{SARAN}

Pada penelitian ini terdapat beberapa saran, seperti berikut :

1. Sebaiknya sensor yang digunakan untuk penelitian selanjutnya menggunakan sensor yang mempunyai datasheet lebih lengkap.

2. Alat yang diciptakan ini masih dalam konsep skala kecil atau prototype dan diharapkan dapat dikembangkan ke area yang lebih luas.

3. Dalam merancang dan membangun alat ini akan kesulitan jika alat ini terkena air. Penulis menyarankan agar alat yang telah dibuat dijauhkan dari air agar alat tersebut tidak rusak dan tidak mengalami kegagalan.

4. Alat ini berhasil dan dapat bekerja sesuai dengan fungsinya sebagai penyiram bibit tanaman otomatis. Tetapi Tidak terdapat monitoring di penampung air ketika penampung air air habis. Sehingga sistemnya dapat di kembangkan untuk penelitianselanjutnya. 


\section{UCAPAN TERIMA KASIH}

Syukur tak lupa saya panjatkan kehadirat Allah SWT atas ridho-Nya lah penelitian ini dapat dilaksanakan, kemudian penulis tak lupa mengucapkan terimakasih kepada kedua orang tua yang telah mensupport dan mendoakan penulis agar diberikan kemudahan dalam menyelesaikan penelitian ini dan terakhir penulis juga tak lupa mengucapkan terima kasih kepada semua pihak yang memberi dukungan sehingga penelitian ini dapat diselesaikan.

\section{DAFTAR PUSTAKA}

[1] Affan Bachri, Wahyu Santoso, Prototype Penyiram Tanaman Otomatis Dengan Sensor Kelembaban Tanah berbasis Atmega 238, (Jurnal JE-Unisla, UIL, Vol 2 No.1, 2017).

[2] Arief Rahman Hakim, Rancang Bangun Prototype Alat Penyiraman Berbasis Mikrokontroler Dengan Sensos Kelembapan Dan Suhu, (Universitas Gunadarma, 2016).

[3] Asniati, dkk, Penerapan Alat Sensor Kelembapan Tanah Dengan Mikrokontroler ATMEGA328 Untuk Penyiraman Tanaman Otomatis, (SEMANASTIKOM, UDI, 2017).

[4] Ashwini B V, A Study on Smart Irrigation System Using Surveillance of Crop-Field, (Internasional Journal Of Engineering \& Tecknology, 2018).

[5]Deddy Prayama, dkk, Rancang Bangun Alat Pengontrol Penyiram Tanaman Otomatis Menggunakan Sensor Kelembaban Tanah Di Area Pertanian, (Jurnal Resti, Vol 2 No.3, 2018).

[6] Jacquline, dkk, Automatic Watering System for Plants with IoT Monitoring and Notification, (Universitas Klabat, Cogito Smart Journal, Vol 4 No.2, 2018).

[7] Julham Polmed, dkk, Development of soil moisture measurement with wireless sensor webbased concept, (IJEECS, Vol 13 No.2, 2018).

[8] Prayitno, W. A., Muttaqin, A., \& Syauqy, D., Sistem Monitoring Suhu, Kelembaban, dan Pengendali Peyiraman Tanaman Hidroponik menggunakan Blynk Android, Pengembangan Teknologi Informasi dan Ilmu Komputer. Vol 1 (4), 292. (2017).

[9]Ratnawati, Silma, Sistem Kendali Penyiram Tanaman Menggunakan Propeller Berbasis Internet Of Things, (Jurnal Inspiraton, STMIK AKBA, Vol 7 No.2, 2017).

[10] Ray Kasful Ghito, Rancang Bangun Smart Garden System Menggunakan Sensor Soil Moisture dan Arduino Berbasis Android, (Universitas Majalengka, 2017).

[11] Wulantika Sintia, dkk, Rancang Bangun Sistem Monitoring Kelembaban Tanah Dan Suhu Udara Berbasis GSM SIM900A Dan Arduino UNO, (Jurnal Kumpuran Fisika, Universitas Bengjulu, Vol 1 No.2, 2018) 